\title{
Recommended Methods of Fatty Acid Methylester Preparation for Conjugated Dienes and Trienes in Food and Biological Samples
}

\author{
Miki Igarashi*, Tsuyoshi Tsuzuki, Tomoko Kambe and Teruo MiYaZAWA** \\ Food \& Biodynamic Chemistry Laboratory, Graduate School of Life Science and Agriculture, \\ Tohoku University, Sendai 981-8555, Japan
}

(Received July 25, 2003)

\begin{abstract}
Summary In this study, we compared three acid-catalyzed methods and three base-catalyzed methods for the methylester preparation of conjugated dienoic fatty acids and conjugated trienoic fatty acids in food and biological samples. Among the six methods examined, the sodium methoxide/methanol $\left(\mathrm{NaOCH}_{3} / \mathrm{MeOH}\right)$ method and the tetramethylguanidine/ methanol (TMG/MeOH) method of methylester preparation from tung oil were most efficient in preventing the artificial isomerization of $\alpha$-eleostearic acid $(\alpha$-ESA; $9 \mathrm{c}, 11 \mathrm{t}, 13 \mathrm{t}$ $18: 3)$ to $\beta$-eleostearic acid ( $\beta$-ESA; $9 \mathrm{t}, 11 \mathrm{t}, 13 \mathrm{t}-18: 3)$ and for avoiding the artificial generation of unknown byproducts. Hydrochloric acid/methanol $(\mathrm{HCl} / \mathrm{MeOH})$, sulfuric acid/methanol $\left(\mathrm{H}_{2} \mathrm{SO}_{4} / \mathrm{MeOH}\right)$ and AOCS (boron trifluoride/methanol $\left(\mathrm{BF}_{3} / \mathrm{MeOH}\right)$ ) methods of methylester preparation from tung oil resulted in the breakdown of $\alpha$-ESA due to their long reaction periods and high reaction temperatures. In addition, these three methods did not prevent the generation of $\beta$-ESA. For the methylester preparation of tung oil free fatty acids, the $\mathrm{BF}_{3} / \mathrm{MeOH}$ method (30 min at room temperature) did not lead to artificial $\beta$-ESA formation or byproducts, while the trimethylsilyldiazomethane $\left(\mathrm{TMSN}_{2} \mathrm{CH}_{3}\right)$ method did form artifacts. For the methylation of conjugated linoleic acid (CLA, free fatty acid), the $\mathrm{BF}_{3} /$ $\mathrm{MeOH}$ and $\mathrm{TMSN}_{2} \mathrm{CH}_{3}$ methods completely suppressed artificial isomerization of c,t-CLA and $\mathrm{t}, \mathrm{c}-\mathrm{CLA}$ to $\mathrm{t}, \mathrm{t}-\mathrm{CLA}$. The results indicated that the $\mathrm{BF}_{3} / \mathrm{MeOH}$ method for free fatty acids is the best method for the methylester preparation of both conjugated dienoic and trienoic fatty acids with respect to preventing artificial isomerization and the formation of byproducts. The $\mathrm{BF}_{3} / \mathrm{MeOH}$ method was applicable to both food and biological samples.
\end{abstract}

Key Words methylation, gas chromatography, conjugated fatty acids, conjugated linoleic acid, eleostearic acid

Some plant seed oils contain conjugated trienoic fatty acids such as $\alpha$-eleostearic acid $(\alpha$-ESA; 9c,11t,13t$18: 3, n-5)$, calendic acid $(8 \mathrm{t}, 10 \mathrm{t}, 12 \mathrm{c}-18: 3, n-6)$, and conjugated tetraenoic acids, such as parinaric acid $(9 \mathrm{c}, 11 \mathrm{t}, 13 \mathrm{t}, 15 \mathrm{c}-18: 4, n-3)(1,2)$. Additionally, bosseopentaenoic acid ( $5 \mathrm{c}, 8 \mathrm{c}, 10 \mathrm{t}, 12 \mathrm{t}, 14 \mathrm{c}-20: 5, n-6)$ and stellaheptaenoic acid $(4 \mathrm{c}, 7 \mathrm{c}, 9 \mathrm{t}, 11 \mathrm{t}, 13 \mathrm{c}, 16 \mathrm{c}, 19 \mathrm{c}-22: 7, n-3)$ have been found in red algae (3-5). Conjugated linoleic acid (CLA; 9c,11t-18:2 and 10t,12c-18:2) exists in many foodstuffs such as milk, cheese, and beef $(6-8)$.

CLA has several physiological effects, including those directed against carcinogenesis, obesity, and atherosclerosis $(6,9,10)$. On the other hand, we have recently reported that conjugated trienoic fatty acids induce apoptosis selectively in human tumor cells more effectively than CLA via membrane phospholipid hydroperoxidation $(11,12)$.

The fatty acid composition of food oils and biological samples is generally analyzed by gas chromatography (GC). Usually before GC analysis, fatty acids are con-

\footnotetext{
*Present address: Sugiyama Human Nutrition Research Center, Sugiyama Jogakuen University, Nagoya 464-8662, Japan

**Correspondence Author.

E-mail: miyazawa@biochem.tohoku.ac.jp
}

verted into their corresponding methylesters using either a base or an acid catalyst. Up to now, CLA has usually been methylated with an acid catalyst (6-8). The problem of these acid-catalyst methods is that the c,t-isomers of CLA have a tendency to be artificially converted into $\mathrm{t}, \mathrm{t}$-isomers during the acid-catalyzed methylation (13). Some methoxyl compounds are also further generated (13). As a result, optimal methods for CLA have been reported $(8,14-16)$. Chin et al. $(8)$ have recommended a hydrochloric acid/methanol $(\mathrm{HCl} / \mathrm{MeOH})$ treatment at $60^{\circ} \mathrm{C}$ for $20 \mathrm{~min}$. Yamasaki et al. (14) have recommended sulfuric acid/methanol methylation $\left(\mathrm{H}_{2} \mathrm{SO}_{4} / \mathrm{MeOH}\right)$ in the presence of either dimethylsulfoxide (DMSO) or dimethylformamide (DMF). Kramer et al. (15) have recommended complicated combinations of sodium methoxide/methanol $\left(\mathrm{NaOCH}_{3} / \mathrm{MeOH}\right)$ followed by hydrochloric acid and boron trifluoride/methanol $\left(\mathrm{BF}_{3} / \mathrm{MeOH}\right)$, or a diazomethane solution followed by $\mathrm{NaOCH}_{3} / \mathrm{MeOH}$.

Despite the physiological importance of dietary conjugated trienoic fatty acids over conjugated dienoic acids, there are no reports on the best method for converting them into methylesters prior to GC analysis. Moreover, it is not clear whether a single method could be used to prepare methylesters of both conjugated 
trienoic fatty acids and conjugated dienoic fatty acids without any artificial isomerization and unwanted byproduct formation. In this study, three base-catalyzed methods and three acid-catalyzed methods were examined for the preparation of methylesters of conjugated trienoic fatty acids and conjugated dienoic acids.

\section{MATERIALS AND METHODS}

Materials. Tung oil (Chinese tung oil) was a gift from NOF Corporation (Tokyo). CLA, prepared from high-linoleic safflower oil, was obtained from Rinoru Oil Mills Company, Ltd. (Tokyo). $\mathrm{BF}_{3} / \mathrm{MeOH}(14 \%, w / v)$ and $\mathrm{NaOCH}_{3} / \mathrm{MeOH}(1 \mathrm{~N})$ solutions were purchased from Wako Pure Chemicals Industries, Ltd. (Osaka). Tetramethylguanidine (TMG) was obtained from Kanto Chemical Company, Inc. (Tokyo). Trimethylsilyldiazomethane $\left(\mathrm{TMSN}_{2} \mathrm{CH}_{3}\right)(10 \%$ in hexane, v/v) was purchased from GL Sciences, Inc. (Tokyo). Tung oil was saponified with $0.2 \mathrm{~N} \mathrm{KOH}$ in ethanol at $40^{\circ} \mathrm{C}$ for $90 \mathrm{~min}$ in order to obtain tung oil free fatty acids. Tung (Aleueites fordii) and cow milk were purchased from a local market. Rats used in this experiment were fed a $1 \%$ tung oil diet for 1 mo (17). Total lipids from tung seeds, cow milk, and rat liver were extracted by the method of Folch et al. (18).

Methylation procedures

Acid-catalyzed methods: The American Oil Chemists' Society (AOCS) method of using a $\mathrm{BF}_{3} / \mathrm{MeOH}$ solution was carried out according to the procedure in the AOCS test manual (19). Briefly, tung oil and CLA (1.0 mg) were heated in $2.0 \mathrm{~mL}$ of $0.5 \mathrm{~N} \mathrm{NaOH} / \mathrm{MeOH}$ in a 10 $\mathrm{mL}$ test tube for $5 \mathrm{~min}$ at $100^{\circ} \mathrm{C}$. Then, $\mathrm{BF}_{3} / \mathrm{MeOH}$ solution $(2.0 \mathrm{~mL})$ was added, and this mixture was heated for $5 \mathrm{~min}$ at $100^{\circ} \mathrm{C}$. The reaction solution was neutralized with $3 \mathrm{~mL}$ of $2 \% \mathrm{KHCO}_{3}$, and then the fatty acid methylesters (FAMEs) were extracted with $n$-hexane.

Tung oil free fatty acids and CLA $(1.0 \mathrm{mg})$ were methylated by the addition of $1.0 \mathrm{~mL}$ of $\mathrm{BF}_{3} / \mathrm{MeOH}$ for $30 \mathrm{~min}$ at room temperature $\left(\mathrm{BF}_{3} / \mathrm{MeOH}\right.$ method) (20).

The $\mathrm{HCl} / \mathrm{MeOH}$ method and $\mathrm{H}_{2} \mathrm{SO}_{4} / \mathrm{MeOH}$ method were carried out according to the procedure of Luddy et al. (21). Tung oil and CLA (1.0 mg) were heated in 1 $\mathrm{mL}$ of $4 \% \mathrm{HCl} / \mathrm{MeOH}$ or $4 \% \mathrm{H}_{2} \mathrm{SO}_{4} / \mathrm{MeOH}$ in a $10-\mathrm{mL}$ test tube for $5-60 \mathrm{~min}$ at $60-100^{\circ} \mathrm{C}$. The reaction mixture was neutralized with $3.0 \mathrm{~mL}$ of $2 \% \mathrm{KHCO}_{3}$, and FAMEs were extracted with $n$-hexane.

Base-catalyzed methods: The $\mathrm{NaOCH}_{3} / \mathrm{MeOH}$ method was carried out according to the procedure of Christin (22). Tung oil $(1.0 \mathrm{mg})$ was dissolved in $2.0 \mathrm{~mL}$ of $1 \mathrm{~N}$ $\mathrm{NaOCH}_{3} / \mathrm{MeOH}$ solution in a 10 -mL test tube. After $5 \mathrm{~min}$ incubation at room temperature, the reaction was stopped by adding $5 \mathrm{~mL}$ of saturated $\mathrm{NaCl}$ solution. FAMEs were then extracted by $n$-hexane.

The tetramethylguanidine (TMG) method was based on the method reported by Schuchartdt and Lopes (23). Briefly, tung oil $(1.0 \mathrm{mg})$ was dissolved in $2.0 \mathrm{~mL}$ of $\mathrm{TMG} / \mathrm{MeOH}(1: 4, \mathrm{v} / \mathrm{v})$ solution in a $10-\mathrm{mL}$ test tube and heated for $2 \mathrm{~min}$ at $100^{\circ} \mathrm{C}$. A saturated $\mathrm{NaCl}$ solution $(5 \mathrm{~mL})$ was added to the resulting mixture, and FAMEs were recovered with $n$-hexane.
The TMSN $\mathrm{CH}_{3}$ method was carried out according to the procedure of Hashimoto et al. (24). Tung oil free fatty acid and CLA (1.0 mg) in $9 \mathrm{~mL}$ of $\mathrm{MeOH} /$ benzene $(2: 7, \mathrm{v} / \mathrm{v})$ was added to $1 \mathrm{~mL}$ of $1.3 \mathrm{mM} \mathrm{TMSN}_{2} \mathrm{CH}_{3}$ in $n$-hexane in a $10-\mathrm{mL}$ test tube. After standing for $30 \mathrm{~min}$ at room temperature, the reaction mixture was dried under a stream of nitrogen gas, and the dried residue was then redissolved in an adequate amount of $n$ hexane.

For all six methods, the hexane extract was subjected to silica gel thin-layer chromatography to confirm the conversion of the sample (lipids and free fatty acids) to methylester.

Gas chromatography. A gas chromatograph (GC 353B, GL Sciences, Inc.) equipped with an FID detector and a Supelcowax-10 fused silica capillary column (60 $\mathrm{m} \times 0.32 \mathrm{~mm}$ i.d., Supelco, Inc., Bellefonte, PA) was used. Helium was used as the carrier gas. The injector and detector temperatures were $200^{\circ} \mathrm{C}$ and $250^{\circ} \mathrm{C}$, respectively. In the case of tung oil fatty acid methylesters, the column oven temperature was increased by $20^{\circ} \mathrm{C} / \mathrm{min}$ from 50 to $220^{\circ} \mathrm{C}$ and held for $31.5 \mathrm{~min}$. In the case of CLA methylesters, the oven temperature was programmed to increase by $20^{\circ} \mathrm{C} / \mathrm{min}$ from 50 to $200^{\circ} \mathrm{C}$ and held for $32.5 \mathrm{~min}$ (25). Peak components were identified by comparing their retention times with those of commercial FAMEs (Funakoshi, Tokyo), and also by analyzing corresponding fatty acid dimethyloxiazoline derivatives by gas chromatography-electron impact/ mass spectrometry (GC-EI/MS; GCMS-QP5050A, Shimadzu Corporation, Kyoto). Methylesters of $\alpha$ - and $\beta$ ESA were also prepared according to the $\mathrm{BF}_{3} / \mathrm{MeOH}$ method described above for which $\alpha$ - and $\beta$-ESA were purified by using reversed-phase high performance liquid chromatography of tung oil free fatty acids. For this purpose, an Inertsil ODS 10 column (4.5 i.d. $\times 250$ $\mathrm{mm}$, GL Sciences, Inc.) was used with a flow rate of $1.5 \mathrm{~mL} / \mathrm{min}$, with a mobile phase consisting of a mixture of acetonitrile and water $(7: 3, \mathrm{v} / \mathrm{v})$.

Gas chromatography-electron impact/mass spectrometry (GC-EI/MS). For the GC-EI/MS analysis, 4,4-dimethyloxazoline derivatives were prepared from the corresponding free fatty acids as follows (26). Each free fatty acid ( $5 \mathrm{mg}$ ) was placed in a $10-\mathrm{mL}$ test tube, followed by 2-amino-2-methyl-1-propanol $(200 \mu \mathrm{L})$. The test tube was purged with nitrogen gas, screw-capped and heated at $170^{\circ} \mathrm{C}$. After $30 \mathrm{~min}$, the tube was cooled, a saturated $\mathrm{NaCl}$ solution $(5 \mathrm{~mL})$ and $n$-hexane $(5 \mathrm{~mL})$ were added, followed by vigorous shaking. After centrifugation, the hexane phase was dried under a stream of nitrogen gas, and the dried residue was then redissolved in an adequate amount of $n$-hexane.

GC-EI/MS was performed using a gas chromatograph (GC-17A, Shimadzu) equipped with a Supelcowax-10 fused silica capillary column coupled to an electron impact mass spectrometer (GCMS-QP5050A, Shimadzu). Helium was used as the carrier gas. The injector temperature was $200^{\circ} \mathrm{C}$. The oven temperature was programmed to match the temperature used in the corresponding GC analysis described above. The tempera- 
ture of the ion source was $250^{\circ} \mathrm{C}$. The electron impact mass spectra were recorded at $70 \mathrm{eV}$ and analyzed using the CLASS 5000 data system (Shimadzu).

\section{RESULTS}

\section{Analysis}

Figure 1 shows GC chromatograms of FAMEs prepared from tung oil free fatty acids using the $\mathrm{BF}_{3} / \mathrm{MeOH}$ method, and FAMEs prepared from tung oil using the $\mathrm{HCl} / \mathrm{MeOH}$ method and the $\mathrm{NaOCH}_{3} / \mathrm{MeOH}$ method. Under the given chromatographic conditions, the retention times of $\alpha$-ESA and $\beta$-ESA were 32.3 and 35.2 min, respectively. As a typical example of GC-EI/MS analysis for fatty acid identification, the mass spectrum of the oxazoline derivative of $\alpha$-ESA is shown in Fig. 2. The molecular ion was at $m / z 331$, and the two fragment peaks at $m / z 182$ and 288 were ascribed to an allylic cleavage of $\alpha$-ESA, which supported the proposed double bond positions. The mass difference of 12 mass units between $\mathrm{m} / \mathrm{z} 196$ and 208, $\mathrm{m} / \mathrm{z} 222$ and 234, and $\mathrm{m} / \mathrm{z} 248$ and 260 indicated that the conjugated double bonds are located at the 9, 11, and 13 positions (ESA). Comparison of acid-catalyzed methylation procedures

The GC chromatogram of FAMEs prepared from tung oil by the $4 \% \mathrm{HCl} / \mathrm{MeOH}$ method (for $20 \mathrm{~min}$ at $60^{\circ} \mathrm{C}$ ) is

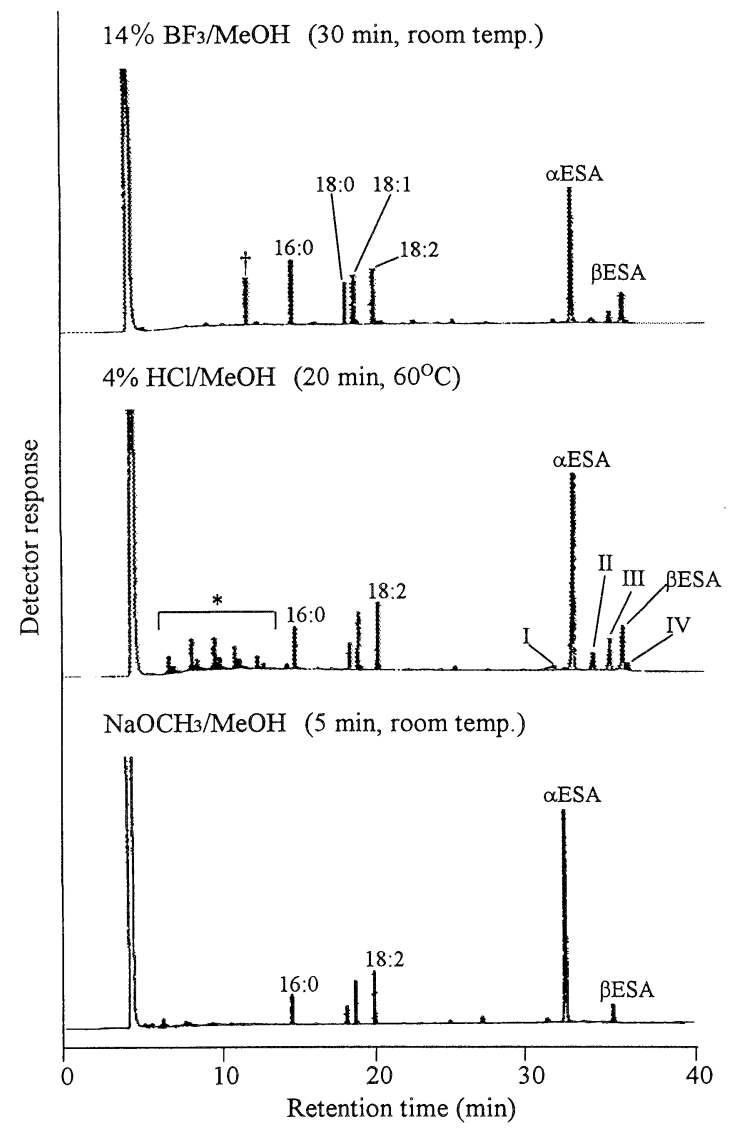

Fig. 1. GC chromatograms of tung oil fatty acid methylesters each preparated with the $14 \% \mathrm{BF}_{3} / \mathrm{MeOH}$ (30 min, room temp.) method, $4 \% \mathrm{HCl} / \mathrm{MeOH}$ (20 min, $60^{\circ} \mathrm{C}$ ) method, and $\mathrm{NaOCH}_{3} / \mathrm{MeOH}(5 \mathrm{~min}$, room temp.) method. † Reagent impurity. *Unidentifiedbreakdown products. given in Fig. 1 (middle). Peaks II and III were confirmed to be 9,11,13-octadecatrienoic acid (ESA, $\mathrm{m} / \mathrm{z} 331$ ) by GC-EI/MS analysis of the dimethyloxazoline derivative. The difference in retention times of peaks II and III were due to a mixture of cis and trans isomers. Peaks I and IV were confirmed to have the same molecular ion at $\mathrm{m} / \mathrm{z}$ 331 as the dimethyloxazoline derivative (equal to ESA), but their geometrical and positional characteristics were not determined.

With the $\mathrm{BF}_{3} / \mathrm{MeOH}$ method, the percentages of $\alpha$ ESA and $\beta$-ESA were determined to be 85.2 and $9.5 \%$, respectively. In the tung oil fatty acid methyl ester preparation, the AOCS method (at $100^{\circ} \mathrm{C}$ for $5 \mathrm{~min}$ ), which is the most popular methylation procedure using $\mathrm{BF}_{3}$, resulted in a decrease in the proportion of $\alpha$-ESA, an increase in artificial $\beta$-ESA, and the appearance of peaks I-IV compared with the $\mathrm{BF}_{3} / \mathrm{MeOH}$ method (for $30 \mathrm{~min}$ at room temperature) (Fig. 1 and Table 1). With the $\mathrm{HCl} / \mathrm{MeOH}$ method and $\mathrm{H}_{2} \mathrm{SO}_{4} / \mathrm{MeOH}$ method (for 5-20 $\mathrm{min}$ at $60-100^{\circ} \mathrm{C}$ ), a methylation period greater than $5 \mathrm{~min}$ and a reaction temperature higher than $60^{\circ} \mathrm{C}$ caused a significant increase in $\beta$-ESA, peak I-IV artificial components, and unknown products (Table 1 ). The GC chromatograms in Fig. 1 indicate that several artifact-breakdown peaks overlapping with intact FAME peaks appeared with the methylation of tung oil by the $\mathrm{HCl} / \mathrm{MeOH}$ method and $\mathrm{H}_{2} \mathrm{SO}_{4} / \mathrm{MeOH}$ method.

For the fatty acid composition of sample CLA, the proportions of 9c,11t-CLA and 10t,12c-CLA were 47.2 and $47.9 \%$, respectively, using the $\mathrm{BF}_{3} / \mathrm{MeOH}$ method (at room temperature for $30 \mathrm{~min}$ ). The compositions of FAMEs prepared with the $\mathrm{TMSN}_{2} \mathrm{CH}_{3}$ method were almost identical to the proportions of CLA methylesters prepared by the $\mathrm{BF}_{3} / \mathrm{MeOH}$ method. In the CLA methylation, the long reaction period for methylation and high temperature associated with the $\mathrm{HCl} / \mathrm{MeOH}$ method and $\mathrm{H}_{2} \mathrm{SO}_{4} / \mathrm{MeOH}$ method tended to cause a significant increase in 9t,11t-/10t,12t-CLA and unknown compounds (Fig. 3 and Table 2). In particular, methylation using the $\mathrm{H}_{2} \mathrm{SO}_{4} / \mathrm{MeOH}$ method at $100^{\circ} \mathrm{C}$ for 20-60 min produced 10c,12t-CLA and 11c,13tCLA isomers, while these isomers were not observed when other methylation methods were used. The AOCS method slightly increased levels of $9 \mathrm{t}, 11 \mathrm{t}-/ 10 \mathrm{t}, 12 \mathrm{t}-$ CLA, and unknown compounds compared with the

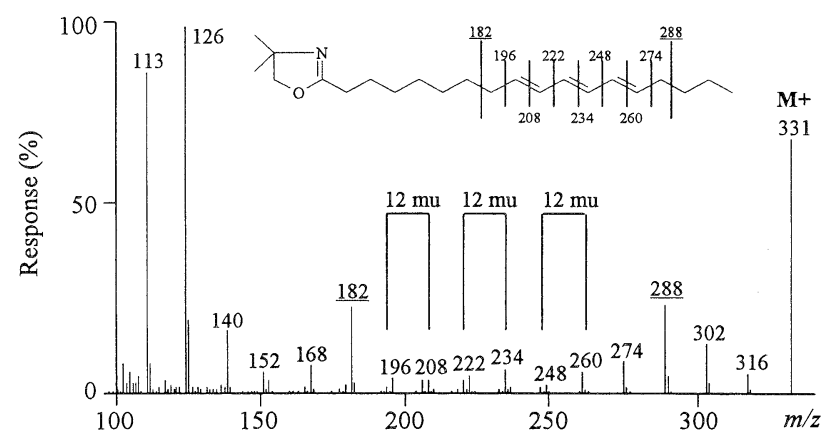

Fig. 2. GC-EI/MS of 4, 4-dimethyloxazoline derivative of $\alpha$-eleostearic acid. Allylic cleavage fragments are underlined. mu, mass unit. 
Table 1. Artificial isomerization of tung oil fatty acids depended on different methylation procedures.

\begin{tabular}{|c|c|c|c|c|c|c|}
\hline \multirow{2}{*}{ Methods* } & \multirow{2}{*}{ Reaction temp. $\left({ }^{\circ} \mathrm{C}\right)$} & \multirow{2}{*}{ Reaction time (min) } & $\alpha$-ESA & $\beta$-ESA & $9,11,13-\operatorname{Ln} A$ & Others \\
\hline & & & \multicolumn{4}{|c|}{ (\% of total conjugated fatty acids) } \\
\hline $\mathrm{AOCS}\left(\mathrm{BF}_{3} / \mathrm{MeOH}\right)$ & 100 & 5 & 67.6 & 17.4 & 10.7 & 4.3 \\
\hline $\mathrm{BF}_{3} / \mathrm{MeOH}$ & RT & 30 & 85.2 & 9.5 & 1.9 & 3.4 \\
\hline \multirow[t]{7}{*}{$\mathrm{HCl} / \mathrm{MeOH}$} & 60 & 5 & 81.9 & 8.3 & 6.1 & 3.6 \\
\hline & 60 & 10 & 72.0 & 10.6 & 12.9 & 4.5 \\
\hline & 60 & 20 & 62.1 & 14.1 & 18.8 & 5.0 \\
\hline & 80 & 5 & 54.3 & 17.0 & 22.3 & 6.4 \\
\hline & 80 & 10 & 26.1 & 26.0 & 38.1 & 9.8 \\
\hline & 100 & 5 & 40.6 & 21.6 & 30.2 & 7.6 \\
\hline & 100 & 10 & 12.9 & 27.9 & 44.1 & 15.2 \\
\hline \multirow[t]{7}{*}{$\mathrm{H}_{2} \mathrm{SO}_{4} / \mathrm{MeOH}$} & 60 & 5 & 84.6 & 8.1 & 3.8 & 3.5 \\
\hline & 60 & 10 & 77.6 & 9.9 & 8.8 & 3.7 \\
\hline & 60 & 20 & 65.5 & 13.2 & 15.8 & 5.5 \\
\hline & 80 & 5 & 75.4 & 10.1 & 9.4 & 5.1 \\
\hline & 80 & 10 & 56.2 & 16.9 & 21.9 & 5.0 \\
\hline & 100 & 5 & 63.2 & 14.4 & 16.6 & 5.8 \\
\hline & 100 & 10 & 37.6 & 22.1 & 31.6 & 8.8 \\
\hline $\mathrm{NaOCH}_{3} / \mathrm{MeOH}$ & $\mathrm{RT}$ & 5 & 91.8 & 6.9 & ND & 1.3 \\
\hline TMG/MeOH & 100 & 5 & 90.8 & 6.6 & 0.4 & 2.1 \\
\hline $\mathrm{TMSN}_{2} \mathrm{CH}_{3}$ & $\mathrm{RT}$ & 30 & 79.7 & 18.7 & 0.5 & 1.1 \\
\hline
\end{tabular}

* For method details see Materials and Methods in the text.

The area of each peak of conjugated fatty acid was divided by the sum of all the peaks of conjugated fatty acids to calculate percentages. 9,11,13-LnA corresponded to Peaks II and III in Fig. 1, and those components of Peaks I and IV and unknown artifacts were calculated as "Others." AOCS: American Oil Chemists' Society, ESA: eleostearic acid, LnA: $\alpha$-linolenic acid, RT: room temperature, TMG: tetramethylguanidine, $\mathrm{TMSN}_{2} \mathrm{CH}_{3}$ : trimethylsilyldiazomethane.

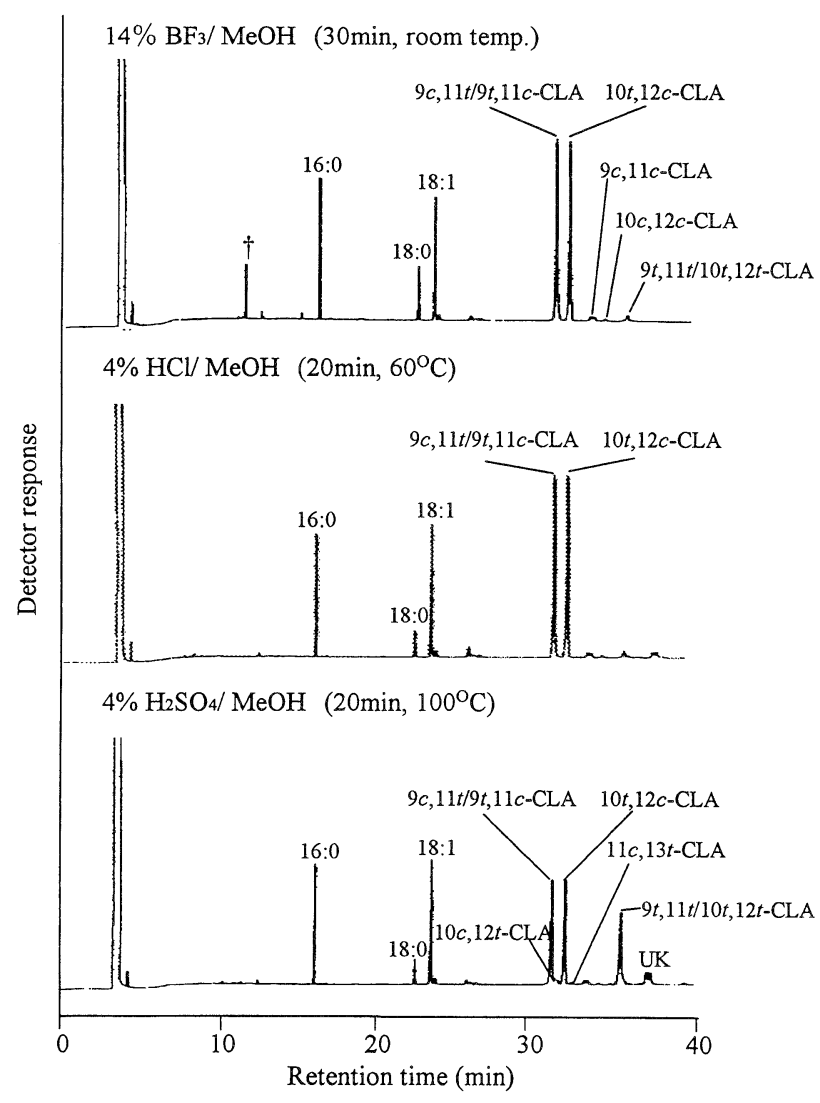

Fig. 3. GC chromatograms of alkali-conjugated safflower oil fatty acid methylesters each prepared with the $14 \% \mathrm{BF}_{3} / \mathrm{MeOH}$ (30 min, room temp.) method, $4 \%$ $\mathrm{HCl} / \mathrm{MeOH}\left(20 \mathrm{~min}, 60^{\circ} \mathrm{C}\right)$ method and $4 \% \mathrm{H}_{2} \mathrm{SO}_{4} /$ $\mathrm{MeOH}\left(20 \mathrm{~min}, 100^{\circ} \mathrm{C}\right)$ method. UK, unknown. † Reagent impurity.
$\mathrm{BF}_{3} / \mathrm{MeOH}$ method (Fig. 3 and Table 2).

The GC chromatograms of tung oil free fatty acids and CLA methylated with the $\mathrm{BF}_{3} / \mathrm{MeOH}$ method revealed an impurity peak with a retention time of 11.5 min († stay marked in Fig. 1 and Fig. 3). This peak component was not a byproduct from sample lipid fatty acids because it also appeared as a reagent impurity of the $\mathrm{BF}_{3} / \mathrm{MeOH}$ solution (Wako). This impurity peak was not detected in the sample lipids methylated with the $\mathrm{BF}_{3} / \mathrm{MeOH}$ solution purchased from another supplier (GL Sciences, Inc.).

Comparison of base-catalyzed methylation procedures

The proportions of $\alpha$-ESA and $\beta$-ESA were 90 and $7 \%$, respectively, of the total conjugated fatty acid methylesters of tung oil prepared with the $\mathrm{NaOCH}_{3} / \mathrm{MeOH}$ method or the TMG/MeOH method (Table 1). Peaks II and III (9,11,13-LnA in Fig. 1 and Table 1) were not detected in the fatty acid methylesters prepared with the $\mathrm{NaOCH}_{3} / \mathrm{MeOH}$ procedure. When tung oil fatty acids were methylated by the TMSN $\mathrm{CH}_{3}$ method, the proportions of $\alpha$-ESA and $\beta$-ESA were 79.7 and $18.7 \%$, respectively, of the total conjugated fatty acid methylesters (Table 1).

The 9t,11t/10t,12t-CLA isomers and an unknown CLA isomer each comprised $0.9 \%$ of the total conjugated fatty acid methylesters prepared using the $\mathrm{TMSN}_{2} \mathrm{CH}_{3}$ method (Table 2).

Ideal method selection and recommended procedure for conjugated fatty acid methylester preparation from food, food oils, and biological samples

Based on quantitative gas chromatographic analysis, 
Table 2. Artificial isomerization of CLA depended on different methylation procedures.

\begin{tabular}{|c|c|c|c|c|c|c|c|c|c|c|}
\hline \multirow{3}{*}{ Methods* } & \multirow{3}{*}{$\begin{array}{c}\text { Incubation } \\
\text { temp. }\left({ }^{\circ} \mathrm{C}\right)\end{array}$} & \multirow{3}{*}{$\begin{array}{l}\text { Incubation } \\
\text { time (min) }\end{array}$} & \multicolumn{8}{|c|}{ CLA isomers } \\
\hline & & & $9 \mathrm{c}, 11 \mathrm{t} / 9 \mathrm{t}, 11 \mathrm{c}$ & $10 \mathrm{c}, 12 \mathrm{t}$ & $10 \mathrm{t}, 12 \mathrm{c}$ & $11 \mathrm{c}, 13 \mathrm{t}$ & $9 \mathrm{c}, 11 \mathrm{c}$ & $10 \mathrm{c}, 12 \mathrm{c}$ & $9 \mathrm{t}, 11 \mathrm{t} / 10 \mathrm{t}, 12$ & $2 \mathrm{t} \mathrm{UK}$ \\
\hline & & & \multicolumn{8}{|c|}{ (\% of total conjugated fatty acids) } \\
\hline $\mathrm{AOCS}\left(\mathrm{BF}_{3} / \mathrm{MeOH}\right)$ & 100 & 5 & 43.7 & —** & 44.6 & - & 0.8 & 0.8 & 6.1 & 4.0 \\
\hline $\mathrm{BF}_{3} / \mathrm{MeOH}$ & RT & 30 & 47.2 & - & 47.9 & - & 1.2 & 1.1 & 2.1 & 0.5 \\
\hline \multirow{9}{*}{$\mathrm{HCl} / \mathrm{MeOH}$} & 60 & 10 & 45.0 & - & 46.0 & - & 1.2 & 1.1 & 2.0 & 4.7 \\
\hline & 60 & 20 & 46.5 & - & 47.2 & - & 1.3 & 1.2 & 2.1 & 1.8 \\
\hline & 60 & 60 & 42.1 & - & 42.5 & - & 1.2 & 1.2 & 4.0 & 9.0 \\
\hline & 80 & 10 & 41.8 & - & 42.8 & - & 1.2 & 1.1 & 3.4 & 9.7 \\
\hline & 80 & 20 & 38.5 & - & 39.5 & - & 1.2 & 1.1 & 6.4 & 13.3 \\
\hline & 80 & 60 & 35.7 & - & 36.0 & - & 1.2 & 1.1 & 9.5 & 16.6 \\
\hline & 100 & 10 & 39.4 & - & 40.3 & - & 1.1 & 1.2 & 5.9 & 12.0 \\
\hline & 100 & 20 & 37.2 & - & 38.1 & - & 0.8 & 0.7 & 9.2 & 14.0 \\
\hline & 100 & 60 & 28.6 & - & 29.6 & - & 0.8 & 0.9 & 28.3 & 11.8 \\
\hline \multirow{9}{*}{$\mathrm{H}_{2} \mathrm{SO}_{4} / \mathrm{MeOH}$} & 60 & 10 & 45.6 & - & 46.6 & - & 1.2 & 1.1 & 2.1 & 3.3 \\
\hline & 60 & 20 & 44.3 & - & 44.8 & - & 0.8 & 0.7 & 2.5 & 7.0 \\
\hline & 60 & 60 & 43.0 & - & 43.4 & - & 1.2 & 1.2 & 3.3 & 7.8 \\
\hline & 80 & 10 & 42.6 & - & 43.8 & - & 1.1 & 1.1 & 3.2 & 8.1 \\
\hline & 80 & 20 & 39.6 & - & 40.8 & - & 1.2 & 1.2 & 5.5 & 11.7 \\
\hline & 80 & 60 & 32.0 & - & 32.8 & - & 1.2 & 1.2 & 17.9 & 15.0 \\
\hline & 100 & 10 & 34.5 & - & 35.6 & - & 1.1 & 1.1 & 14.1 & 13.6 \\
\hline & 100 & 20 & 28.5 & 0.6 & 28.4 & 0.7 & 1.2 & 1.2 & 26.3 & 13.2 \\
\hline & 100 & 60 & 16.6 & 5.2 & 13.4 & 2.0 & 0.9 & 0.8 & 49.5 & 11.6 \\
\hline $\mathrm{TMSN}_{2} \mathrm{CH}_{3}$ & RT & 30 & 48.0 & - & 48.8 & - & 0.7 & 0.7 & 0.9 & 0.9 \\
\hline
\end{tabular}

* For method details see Materials and Methods in the text. ** Not detected.

The area of each peak of conjugated fatty acid was divided by the sum of all the peaks of conjugated fatty acids to calculate percentages. AOCS: American Oil Chemists' Society, CLA: conjugated linoleic acid, RT: room temperature, UK: unknown artifacts, TMG: tetramethylguanidine, $\mathrm{TMSN}_{2} \mathrm{CH}_{3}$ : trimethylsilyldiazomethane.

we concluded that the $14 \% \mathrm{BF}_{3} / \mathrm{MeOH}$ method carried out at room temperature for $30 \mathrm{~min}$ is the best method for methylester preparation of both conjugated trienoic fatty acids and conjugated dienoic fatty acids (Scheme 1). The hexane extract was subjected to silica gel thinlayer chromatography to confirm the conversion of the sample $(0-2 \mathrm{mg}$ free fatty acids) to methylester. Moreover the artificial conversion was not changed by the sample amount (0-2 mg free fatty acids).

The typical GC chromatograms are shown in Fig. 4. With this method, $\alpha$-ESA and $\beta$-ESA from tung seeds accounted for 40.8 and $1.3 \%$ of the total fatty acids, respectively (Fig. 4, upper). In contrast, the $4 \% \mathrm{HCl} /$ $\mathrm{MeOH}$ method $\left(60^{\circ} \mathrm{C}\right.$ for $\left.20 \mathrm{~min}\right)$ decreased the $\alpha$-ESA to $27.2 \%$ and increased the $\beta$-ESA to $4.8 \%$ of the total fatty acids in tung seeds, and resulted in the formation of artificial products (Fig. 1, Peaks I-IV). 9t,11c-CLA was detected in the total lipids of livers of rats fed $\alpha$-ESA (Fig. 4, middle) (17), $\alpha$-ESA was also detected in the liver lipids. In cow milk lipids, 9c,11t-CLA and 9t,11tCLA were observed after methylester preparation at 1.0 and $0.2 \%$, respectively, of the total with either the $\mathrm{BF}_{3} /$ $\mathrm{MeOH}$ method or the $\mathrm{HCl} / \mathrm{MeOH}$ method.

\section{DISCUSSION}

Methylation of fatty acids can be performed with either base-catalyzed or acid-catalyzed procedures. In our present study, base-catalyzed methylation of tung oil using the $\mathrm{NaOCH}_{3} / \mathrm{MeOH}$ method and the TMG/ $\mathrm{MeOH}$ method were better than the acid-catalyzed

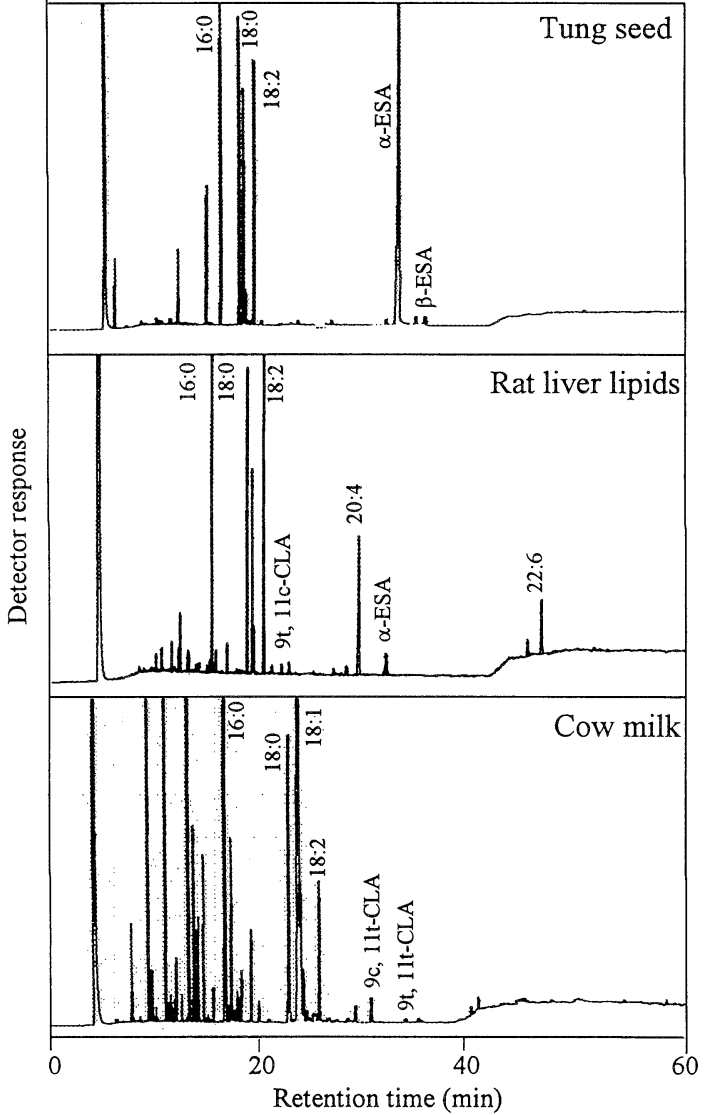

Fig. 4. GC chromatograms of fatty acid methylester preparation by the $\mathrm{BF}_{3} / \mathrm{MeOH}$ method from karela seed lipids, rat liver lipids (fed tung oil diet), and cow milk lipids. 


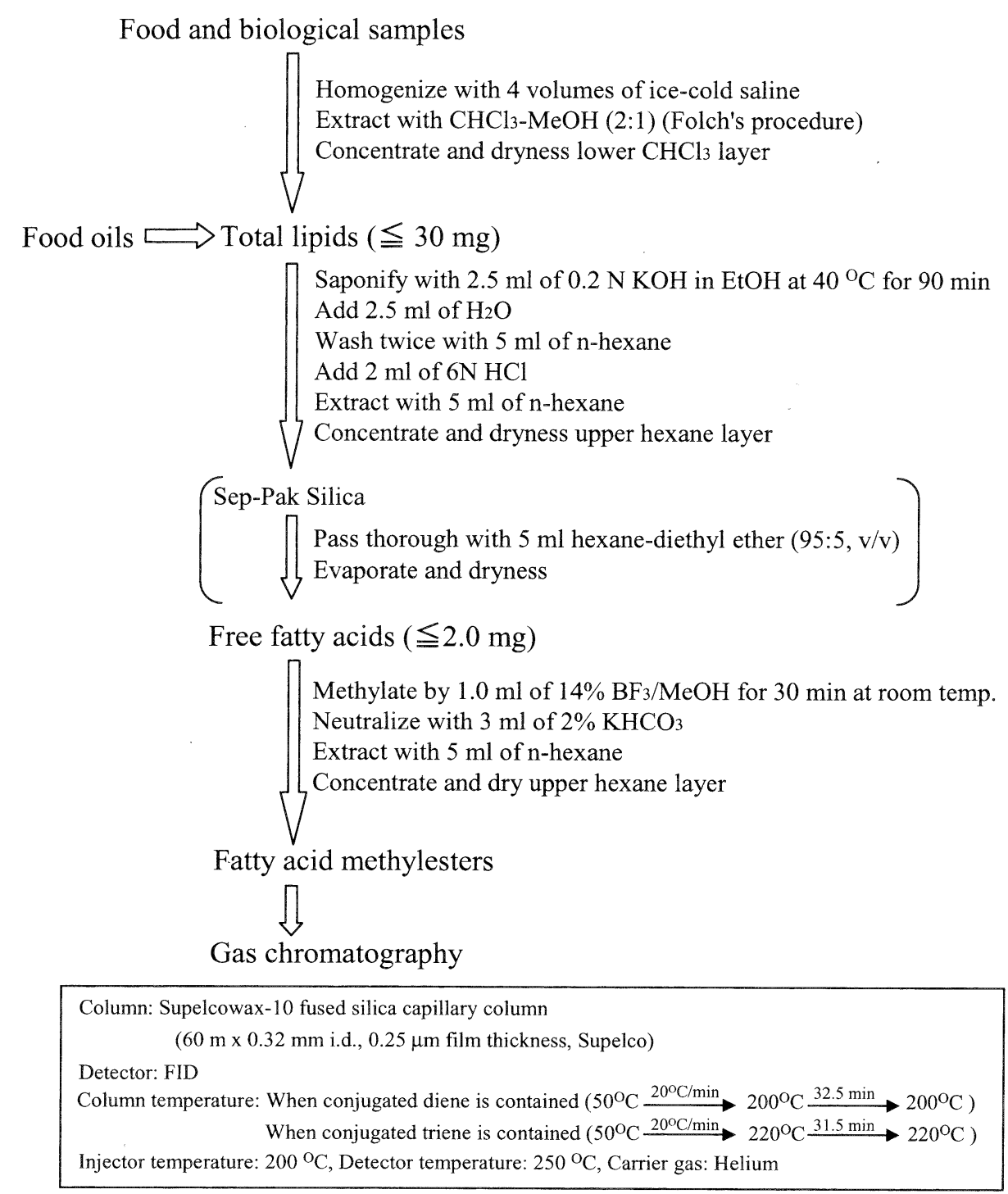

Scheme 1. Recommended procedure for conjugated fatty acid methylester preparation with the boron trifluoride/methanol $\left(\mathrm{BF}_{3} / \mathrm{MeOH}\right)$ method.

methods $\left(\mathrm{HCl} / \mathrm{MeOH}, \mathrm{H}_{2} \mathrm{SO}_{4} / \mathrm{MeOH}\right.$ and $\mathrm{BF}_{3} / \mathrm{MeOH}$ methods) in preventing isomerization of $\alpha$-ESA into $\beta$ ESA and in forming unwanted byproducts. This is consistent with the general notion that base-catalyzed methods provide more stable conditions than do acidbased methods. For example, Spitzer et al. (27) used the TMG method (as a base-catalyzed method) in the detection of conjugated fatty acids in test seed oils. However, base-catalyzed methods do not work for the methylation of all types of lipids. For example, the $\mathrm{NaOCH}_{3} /$ $\mathrm{MeOH}$ method failed to methylate free fatty acids or $\mathrm{N}$ acyl lipids (28), and the TMG/MeOH method failed to methylate constituent fatty acids of sphingomyeline and phospholipids (29). Accordingly, base-catalyzed methods have not been widely used in spite of providing more stable conditions than do the acid-catalyzed methods. Although we could not methylate CLA with the $\mathrm{NaOCH}_{3} / \mathrm{MeOH}$ method or the TMG/MeOH method, Kramer et al. (15) reported that these methods produced no methoxy artifacts in milk lipids containing lipid classes esterified with CLA. Thus, base-catalyzed methylation methods may be advantageous in regards to the lipid configuration of samples.

The TMSN $\mathrm{CH}_{3}$ method, a base-catalyzed procedure, allows stable substitution of the diazomethane method (24). This method prevents the isomerisation of c,t-CLA into t,t-CLA (Table 2), but increases the amount of $\beta$ ESA and byproducts from the methylation of tung oil free fatty acids (for $30 \mathrm{~min}$ at room temperature) (Table $1)$. Under the same conditions, the $\mathrm{BF}_{3} / \mathrm{MeOH}$ method, an acid-catalyzed procedure, is relatively reliable for both tung oil free fatty acids and CLA (Tables 1 and 2). Park et al. (16) also reported that though the $\mathrm{TMSN}_{2} \mathrm{CH}_{3}$ method is mild, it incompletely methylates, generates byproducts, and generates impurities that interfere with GC analysis of short-chain fatty acids. Consequently, we suggest that the $\mathrm{TMSN}_{2} \mathrm{CH}_{3}$ method is not suitable for the methylation of conjugated trienoic and dienoic fatty acids.

On the other hand, acid-catalyzed methods were able to methylate fatty acids in all classes of widely used lipids. However, these methods require a high temperature 
and have been reported to change the proportion of the CLA isomers, and have also been known to generate allylic methoxide from CLA $(13,14)$. We used the $\mathrm{HCl} /$ $\mathrm{MeOH}$ method (at $60^{\circ} \mathrm{C}$ for $20 \mathrm{~min}$ ) to methylate CLA, using conditions recommended by Pariza et al. $(8,25)$. However, even under these conditions, isomerization of the conjugated trienoic fatty acid could not be prevented (Table 1). Yamasaki et al. (14) recommended using the $\mathrm{H}_{2} \mathrm{SO}_{4} / \mathrm{MeOH}$ method in the presence of a certain amount of DMSO or DMF for the esterification of conjugated dienoic fatty acids. They stated that the DMSO and DMF interact with the protonated alcohol, and as a result the isomerization to the t,t-isomer and the generation of methoxy composites are prevented. Their method may also be effective for methylester preparation of conjugated trienoic fatty acids.

None of the methods we studied can methylate conjugated fatty acids problem-free. For milk fatty acids, Kramer et al. (15) recommended using $\mathrm{NaOCH}_{3}$ followed by either $\mathrm{HCl}$ or $\mathrm{BF}_{3}$, or using diazomethane followed by $\mathrm{NaOCH}_{3}$. We also propose that these methods are suitable for the methylation of conjugated trienoic fatty acids.

In conclusion, we recommend the $14 \% \mathrm{BF}_{3} / \mathrm{MeOH}$ procedure (free fatty acids as a sample, at room temperature for $30 \mathrm{~min}$ ) for methylester preparation of both conjugated trienoic fatty acids and conjugated dienoic fatty acids in food, food oils, and biological samples (see Scheme 1).

\section{REFERENCES}

1) Hopkins CY. 1972. Fatty acids with conjugated unsaturation. In: Topics in Lipid Chemistry (Gunstone FD, ed), p 37-87. ELEK Science, London.

2) Badami RC, Patil KB. 1981. Structure and occurrence of unusual fatty acids in minor seed oils. Prog Lipid Res 19: 119-153.

3) Lopez A, Gerwick WH. 1987. Two new icosapentaenoic acids from the temperate red seaweed Ptilota filicina J. Agardh. Lipids 22: 190-194.

4) Burgess JR, de la Rosa RI, Jacobs RS, Butler A. 1991. A new eicosapentaenoic acid formed from arachidonic acid in the coralline red algae Bossiella orbigniana. Lipids 26: $162-165$.

5) Mikhailova MV, Bemis DL, Wise ML, Gerwick WH, Norris JN, Jacobs RS. 1995. Structure and biosynthesis of novel conjugated polyene fatty acids from the marine green alga Anadyomene stellate. Lipids 30: 583-589.

6) Pariza MW. 1987. Anticarcinogens from fried ground beef: heat-altered derivatives of linoleic acid. Carcinogenesis 8: 1881-1887.

7) Lin H, Boylston TD, Chang MJ, Luedecke LO, Shultz TD. 1995. Survey of the conjugated linoleic acid contents of dairy products. J Dairy Sci 78: 2358-2365.

8) Chin SF, Liu W, Storkson JM, Ha YL, Pariza MW. 1992. Dietary sources of conjugated dienoic isomers of linoleic acid, a newly recognized class of anticarcinogens. J Food Comp Anal 5: 185-197.

9) Park Y, Albright KJ, Liu W, Storkson JM, Cook ME, Pariza MW. 1997. Effect of conjugated linolenic acid on body composition in mice. Lipids 32: 853-858.

10) Lee KN, Kritchevsky D, Pariza MW. 1994. Conjugated linoleic acid and atherosclerosis in rabbits. Atherosclerosis 108: 19-25.

11) Igarashi M, Miyazawa T. 2000. Do conjugated eicosapentaenoic acid and conjugated docosahexaenoic acid induce apoptosis via lipid peroxidation in cultured human tumor cells? Biochem Biophys Res Commun 270: 649-656.

12) Igarashi M, Miyazawa T. 2000. Newly recognized cytotoxic effect of conjugated trienoic fatty acids on cultured human tumor cells. Cancer Lett 148: 173-179.

13) Werner AS, Luedecke LO, Shultz TD. 1992. Determination of conjugated linoleic acid in three cheddar-type cheeses: effects of cheese cultures, processing, and aging. J Agric Food Chem 40: 1817-1821.

14) Yamasaki M, Kishihara K, Ikeda I, Sugano M, Yamada K. 1999. A recommended esterification method for gas chromatographic measurement of conjugated linoleic acid. J Am Oil Chem Soc 76: 933-938.

15) Kramer JKG, Fellner V, Dugan MER, Sauer FD, Mossoba MM, Yurawecz MP. 1998. Evaluating acid and base catalysts in the methylation of milk and rumen fatty acids with special emphasis on conjugated dienes and total trans fatty acids. Lipids 32: 1219-1228.

16) Park Y, Albright KJ, Cai ZY, Pariza MW. 2001. Comparison of methylation procedures for conjugated linoleic acid and artifact formation by commercial (trimethylsilyl) diazomethane. J Agric Food Chem 49: 1158-1164.

17) Tsuzuki T, Igarashi M, Komai M, Miyazawa T. 2003. Significant occurrence of 9,11-conjugated linoleic acid $(18: 2, n-7)$ in the liver and plasma lipids of rats fed 9,11,13-eleostearic acid (18:3, $n$-5)-supplemented diet. J Nutr Sci Vitaminol 49: 1-6.

18) Folch J, Lees M, Sloane Stanley GH. 1957. A simple method for the isolation and purification of total lipids from animal tissues. J Biol Chem 226: 497-509.

19) American Oil Chemists' Society. 1973, revised to 1990. Method Ce 1b-89. In: Official Methods and Recommended Practices of the American Oil Chemists' Society (Firestone D, ed). Champaign, Illinois.

20) Morrison WR, Smith LM. 1964. Preparation of fatty acid methyl esters and dimethylacetals from lipids with boron fluoride-methanol. J Lipid Res 5: 600-608.

21) Luddy FE, Barford RA, Riemenschneider RW. 1960. Direct conversion of lipid components to their fatty acid methyl esters. J Am Oil Chem Soc 37: 447-450.

22) Christin WW. 1982. A simple procedure for rapid transmethylation of glycerolipids and cholesteryl ester. J Lipid Res 23: 1072-1075.

23) Schuchardt U, Lopes OC. 1988. Tetramethylguanidine catalyzed transesterification of fats and oil: a new method for rapid determination of their composition. J Am Oil Chem Soc 65: 1940-1941.

24) Hashimoto N, Aoyama T, Shioiri T. 1981. New methods and reagents in organic synthesis. 14. A simple efficient preparation of methyl esters with trimethylsilyldiazomethane $\left(\mathrm{TMSCHN}_{2}\right.$ ) and its application to gas chromatographic analysis of fatty acids. Chem Pharm Bull 29: 1475-1478.

25) Igarashi M, Miyazawa T. 2001. The growth inhibitory effect of conjugated linoleic acid on a human hepatoma cell line, HepG2, is induced by a change in fatty acid metabolism, but not the facilitation of lipid peroxidation in the cells. Biochim Biophys Acta 1530: 162-171.

26) Fay L, Richli U. 1991. Location of double bounds in polyunsaturated fatty acids by gas chromatography- 
mass spectrometry after 4,4-dimethyloxazoline derivatization. J Chromatogr 541: 89-98.

27) Spitzer V, Marx F, Maia JGS, Pfeilsticker K. 1991. Identification of conjugated fatty acids in the seed oil of Acioa edulis (Prance) syn. Couepis edlius (Chrysobalanaceae). J Am Oil Chem Soc 68: 183-189.
28) Christin WW. 1982. Lipid Analysis. Pregamon Press, Oxford.

29) Belury MA, Kempa-Steczko A. 1997. Conjugated linoleic acid modulates hepatic lipid composition in mice. Lipids 32: 199-204. 